\title{
Professor Upendra Prasad Devkota MBBS, FRCS, FNAMS (1953-2018)
}

With profound sadness and tears I write the obituary for Prof. Devkota the pioneer Neurosurgeon from this country.

He was born in Gorkha, Nepal on 18 December 1953 and completed his MBBS from Assam Medical College, Dibrugarh in 1978. After working for few years in Nepal he went for his Neurosurgical training to United Kingdom and trained under the likes of Prof. Teasdale in Glasgow and in Atkinson Morley Hospital. He then returned in 1989 to start the first neurosurgical services in Bir hospital, Kathmandu where specialized care for Oncology, Tumor, Spine, Vascular,Trauma and other fields of Neurosurgery was started. He was also appointed Health Minister under erstwhile, His Majesty's Government and was the founder of the National Academy of Medical Sciences, for the post graduate medical studies in Nepal.

He was the first Neurosurgeon of Nepal, innovatorand scientist, who always stood for the right of doctors. He invented implants, developed techniques and established guidelines for Neurosurgical care. He is the aspiration for more than a dozen Neurosurgeons in Nepal. He was the founder President of SAARC Neurosurgical Society and Director of National Institute of Neurological Sciences, Bansbari, Kathmandu which he established. He was also the recipient of numerous National and International awards.He succumbed to advanced stage Cholangiocarcinoma on 18 June 2018 and is survived by his wife Dr Madhu Dixit and three daughters.

Dr Yam Bahadur Roka

Editor in Chief, NJNS 